\title{
The Influence of Eggshell as Coarse Aggregate Replacement in Hot Mix Asphalt
}

\author{
$\mathrm{Ng}$ Cui Ming*, Ramadhansyah Putra Jaya, Haryati Awang \\ Department of Civil Engineering, College of Engineering, Universiti Malaysia Pahang, 26300 Kuantan, Malaysia
}

\begin{abstract}
Hot Mix Asphalt (HMA) is the most commonly used in Malaysia for highways, interstates and roads due to its flexibility, economical, strong and provide safe riding quality for road users. Over the years, the increase of damage on pavement roads in Malaysia has become a severe issue although the road did not achieve its design life. Hence, to reduce damage and defect, an improvised road pavement structures is needed. Various studies have been conducted to identify the new materials that can be used as a replacement in hot mix asphalt. In this research, the purpose is to evaluate the performance of eggshell as coarse aggregate replacement in hot mix asphalt. The gradation for aggregate used in this mixture is AC14. The weight for total mixing of the aggregates used is $1200 \mathrm{~g}$ while the grade for bitumen is $60 / 70$. The samples were mixed with eggshell in the various percentages of $0 \%, 5 \%, 10 \%, 15 \%$ and $20 \%$ by total weight of aggregate size $5 \mathrm{~mm}$. The laboratory tests carried out to determine the properties of aggregates included, aggregate impact value and aggregate crushing value. Besides, penetration and softening point were also performed to determine the properties of bitumen. Several types of test were conducted towards the samples, which are Marshall Test, Indirect Tensile Strength and Cantabro Test. The results exhibit that the conventional asphalt mixture is more effective than modified asphalt mixture. The replacement of eggshell as coarse aggregate was not enough improvement to the performance of asphalt pavement as the performance of conventional mixture is more stable than modified mixture.
\end{abstract}

\section{ARTICLE HISTORY}

Received: $5^{\text {th }}$ March 2021

Revised: $29^{\text {th }}$ March 2021

Accepted: $8^{\text {th }}$ April 2021

KEYWORDS

Eggshell;

Marshall Test;

Indirect Tensile Strength :

Cantabro Test

\section{INTRODUCTION}

A good pavement quality consist of especially at the surfacing layers, ensures smooth riding and reduces the possibility of unnecessary road accidents [1]. Over the years, lots of maintenance work need to be repaired to minimize the damage on the road pavements [2]. The problem of the dense traffic and heavy loading will give the effect to the road pavements such as cracking and will reduce the pavements life. In addition, Malaysia weather is leading to the damage of road pavement and leaving the big potholes. Asphalt cannot withstand drastic weather changes because the properties of asphalt are hard in a cold environment and soft in a hot climate [3].

Malaysia is one of the largest egg consumption countries in the world. According to Department of Veterinary Service Malaysia data showed that over the past 15 years, the growth of eggs production was equivalent to $4 \%$ per year which is faster than the growth of human population which is only $2 \%$ per year [4]. Disposal of the waste eggshell is a serious environmental concern in many countries [5]. This is because disposal eggshell needs a lot of landfills and the eggshell waste will release the unpleasant smell and cause the growth of bacteria which can cause disease and allergies. The main ingredient in an eggshell is calcium carbonate $\left(\mathrm{CaCO}_{3}\right)$. About $95 \%$ of the dry eggshell is calcium carbonate weighing $5.5 \mathrm{~g}$ [6]. The remaining 5\% includes Magnesium, Aluminium, Phosphorous, Sodium, Potassium, Zinc, Iron, Copper, Ironic acid and Silica acid. Eggshell has a cellulosic structure and contains amino acids. Thus, it is expected to be a good bio-sorbent, and it was reported that large amounts of eggshells are produced in some countries, as waste products and disposed of in landfills annually.

Eggshell can be used to develop novel pavement materials that can withstand traffic loadings and environmental conditions. By review the possibility of incorporating eggshell to improve the performance of hot mix asphalt. A study by Erfen and Mohd [7] reported that the effective eggshell content in an asphalt mixture was in the range of 3\% to 5\%. Their study found that by using eggshell as a filler can reduce the specific gravity of the sample. Kiruthiha et al [8] has used eggshell as a filler to fill the air voids of the asphalt mixture. The result shows that the eggshell is suitable to be applied in the road construction and its addition in the range of $10-15 \%$ in the bituminous mix with OBC of 6-6.5\% gives better strength compared to conventional mix. The performances of eggshell powder asphalt mixture in terms of physical properties and mechanical properties were decrease in penetration and the rotational viscosity as well as a valuable increase in flashpoint versus increasing percent of the eggshell [9]. According to Yuliarahmadila et al [10], the use of eggshell as filler in hot mix asphaltic concrete (AC14) about 3-5\% produce a positive result and fulfil the Malaysia Standard Specification for Road Works (JKR/SPJ/2008-S4) [11]. Therefore, this study presents the influence of eggshell as coarse aggregate replacement in hot mix asphalt. This investigation focused on using the variation of eggshell from $0 \%$ to $20 \%$ to find the optimum percentage that can replace the coarse aggregate in the Hot Mix Asphalt (HMA). 


\section{MATERIALS AND METHODS}

\section{Materials Properties}

Hot asphalt mixtures were prepared according to the Malaysia Standard Specification for Road Works. The aggregate gradation used in this study conformed to JKR/SPJ/2008-S4 [11] specifications for asphaltic concrete AC14. The bitumen used in this study was a 60/70 penetration grade. All mixes consisted of one conventional asphalt mixture and three modified asphalt mixture with different percentages of eggshell $(5 \%, 10 \%, 15 \%$ and $20 \%)$. The dry process technique was used, where the eggshell was added to the aggregate before adding the bitumen. The modified hot asphalt mixtures were compared with the conventional asphalt mixture. The aggregates were divided into batches according to the percentage passing on each size. Table 1 shows the gradation limit for AC14.

Table 1. Gradation limits for AC14 (JKR 2008) [11]

\begin{tabular}{cc}
\hline BS Sieve Size $(\mathrm{mm})$ & Percentage Passing by Weight \\
\hline 20.0 & 100 \\
14.0 & $90-100$ \\
10.0 & $76-86$ \\
5.0 & $50-62$ \\
3.35 & $40-54$ \\
1.18 & $18-34$ \\
0.425 & $12-24$ \\
0.150 & $6-14$ \\
0.075 & $4-8$ \\
\hline
\end{tabular}

\section{Aggregate Impact Value}

The test is to determine the aggregate impact value of road stone and eggshell and also to assess their suitability in road construction on the basis of impact value. The aggregate with size passing $14 \mathrm{~mm}$ and retained on $10 \mathrm{~mm}$ was used. Aggregate was placed in the mould in 3 layers and tapping each layer with 25 time rodding. The specimen is subjected to 15 times impacts from a dropping weight. This action will break the aggregate to a degree which is dependent on the impact resistance of the material. This degree was assessed by sieve analysis test on the impact specimen using $2.36 \mathrm{~mm}$ sieve size and it is taking as aggregate impact value (AIV). The test was carried out in accordance with BS EN 10972:2020 [12]. The percentage of fines of Aggregate Impact Value (AIV) can be calculated by using equation Equation 1.

$$
\text { Percentage fines }=\frac{\text { Weight Loss }\left(M_{3}\right)}{\text { Initial Weight }\left(M_{1}\right)} \times 100 \%
$$

\section{Aggregate Crushing Value}

The test is to determine the mechanical strength of the aggregate and eggshell. The aggregate with size passing $14 \mathrm{~mm}$ and retained on 10mm was used. Aggregate was placed in the mould in 3 layers and tapping each layer with 25 time rodding. The sample is placed between the platens of the testing machine and is located in a uniform rate so that the required $400 \mathrm{kN}$ is reached in 10 minutes. Sieve the specimen using $2.36 \mathrm{~mm}$ sieve size and it is taking as aggregate crushing value (ACV). The test was carried out in accordance with BS EN 1097-2:2020 [12]. The percentage of fines of Aggregate Crushing Value can be calculated by using Equation 2.

$$
\text { Percentage fines }=\frac{\text { Weight Loss }\left(M_{3}\right)}{\text { Initial Weight }\left(M_{1}\right)} \times 100 \%
$$

\section{Softening Point}

The softening point of bitumen using a ring and ball apparatus immersed in distilled water. Determination of softening point can ensure the quality of bitumen in resulting to produce good pavement for the road construction. The bitumen is melted and the liquid is poured into a pair of a ring placed on a plate. The thermometer is placed in the centre of ring holder levelled with the bottom of the ring. After the specimen has cool, the ring is suspended in the distilled water in the beaker $5^{\circ} \mathrm{C}+2^{\circ} \mathrm{C}$. Beaker temperature is maintained at that temperature for 15 minutes. The steel balls are put on the surface of the bitumen in the ring. The beaker liquid is stirred and heated to $5^{\circ} \mathrm{C}+2^{\circ} \mathrm{C}$ per minute. Temperature is noted just after the ball is passed and dropped into the base plate. The test was carried out in accordance with BS EN 1427:2015 [13]. 


\section{Penetration}

This test is to determine the consistency of bituminous material and also to assess the suitability of bitumen for the use when under different climatic conditions and during various types of construction. Specimens are prepared in sample containers and placed in a water bath at the prescribed temperature of test for 1 to 1.5 hours before the test. The needle is lowered slowly until its tip just makes contact with its image on the surface of the sample at right angles. The penetrometer dial reading is set to zero and the needle holder is released to penetrate the bitumen for $5+0.1 \mathrm{~s}$, while the temperature of the specimens is maintained at $25+0.1^{\circ} \mathrm{C}$. The penetration is measured in tenths a millimetre (deci-millimetre, dmm). The test was performed based on procedures described in BS EN 1426:2015 [14].

\section{Marshall Mix Design}

The Marshall method used a standard specimen, and the main purpose of the design was to obtain optimum bitumen content for each mix. In the laboratory, the aggregate, bitumen and eggshell were respectively mixed and compacted at $180 \pm 0.5^{\circ} \mathrm{C}$. The mixes were compacted with 75 blows on each side with the standard Marshall hammer to avoid disintegration of materials. After compaction, the specimens were removed from the molds and allowed to cool down. The specimens were tested for bulk specific gravity as specified in ASTM D 2726 [15]. Firstly take the mass of dry specimen in air, then specimens were completely submerge in the water for 3 to 5 minutes and take the mass in air. The surface were dried and mass of specimen in air was determine. Maximum theoretical specific gravity has been determined, the stability and flow tests are conducted. The specimens were immersed in the water bath at $60^{\circ} \mathrm{C}$ for 40 minutes. It was then place in Marshall Stability testing machine and loaded at constant rate of deformation, until failure occur. The stability result was recorded as the flow for the specimens. Besides that, theoretical maximum density (TMD) was used to determine the void in total mix (VTM) for the specimens. The purpose of the Marshall Stability and Flow test were to determine the Marshall stability and flow values of asphalt mixture. The maximum allowable aggregate size in this experiment is $25 \mathrm{~mm}$ and it is conducted based on ASTM D1559. The parameters that were obtained in this research include stability, flow, stiffness, bulk density, air voids (AV), Voids Filled with Asphalt (VFA) and Voids in the Mineral Aggregates (VMA). Each parameter requires a specific range to be fulfilled accordance with the Malaysian Standard Specification for Road Works [11]. Figure 1 shows the apparatus for Marshall Test.
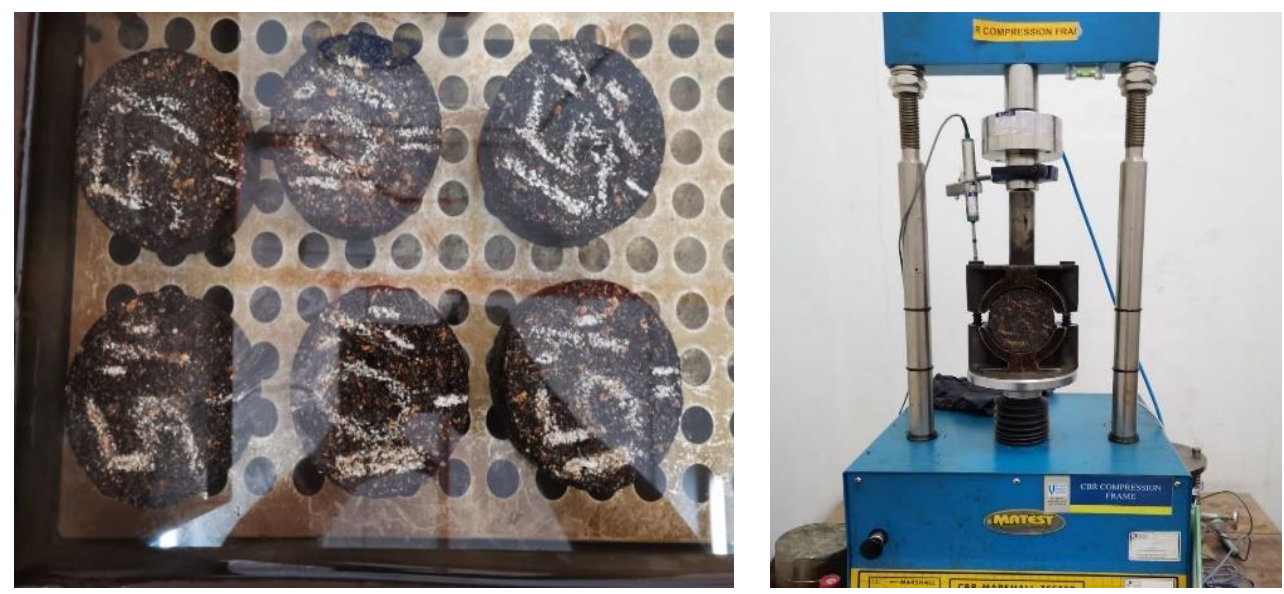

Figure 1. Marshall Test

\section{Indirect Tensile Strength}

Indirect tensile strength is a destructive test applied to the vertical diameter plane of the sample to investigate the cracking resistance of the mixture owing to ambient temperature. Marshall Design Method was used to prepare the samples for ITS, which was carried out in according to the ASTM D6391-12 [16]. The samples were conditioned at $25^{\circ} \mathrm{C}$ in the Universal Testing Machine (UTM) for 4 hours prior to testing. The samples were then tested using Universal Compression Machine with Indirect tensile loading fixture. Figure 2 shows the arrangement of the equipment for ITS. The ITS value can be calculated by using Equation 3.

$$
S=\frac{2 P}{\pi t D}
$$

Where,

$\mathrm{P}=$ maximum load, $\mathrm{kN}$

$\mathrm{t}=$ specimen height immediately before test, $\mathrm{m}$

$\mathrm{D}=$ specimen diameter, $\mathrm{m}$ 


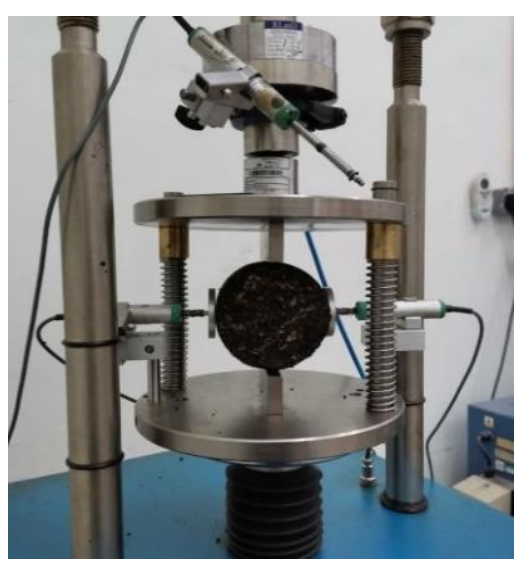

Figure 2. Indirect tensile strength test equipment used

\section{Cantabro Test}

Cantabro test was carried out in according to the ASTM D7064-08. The Cantabro testing involves recording the initial weight of individual sample, placing it in the LA abrasion, and then rotating it for 300 revolutions at the rate of 30 revolutions per minute. $150 \mathrm{~mm}$ diameter by $100 \mathrm{~mm}$ height cylinder specimens were used in the test. Figure 3 shows the sample after 300 revolutions in LA abrasion. The weight loss after the Cantabro test called Cantabro Loss is calculated in percentage using Equation 4.

$$
\text { Cantabro Loss }=\frac{\text { Initial Sample Weight }- \text { Final Sample Weight }}{\text { Initial Sample Weight }} \times 100 \%
$$

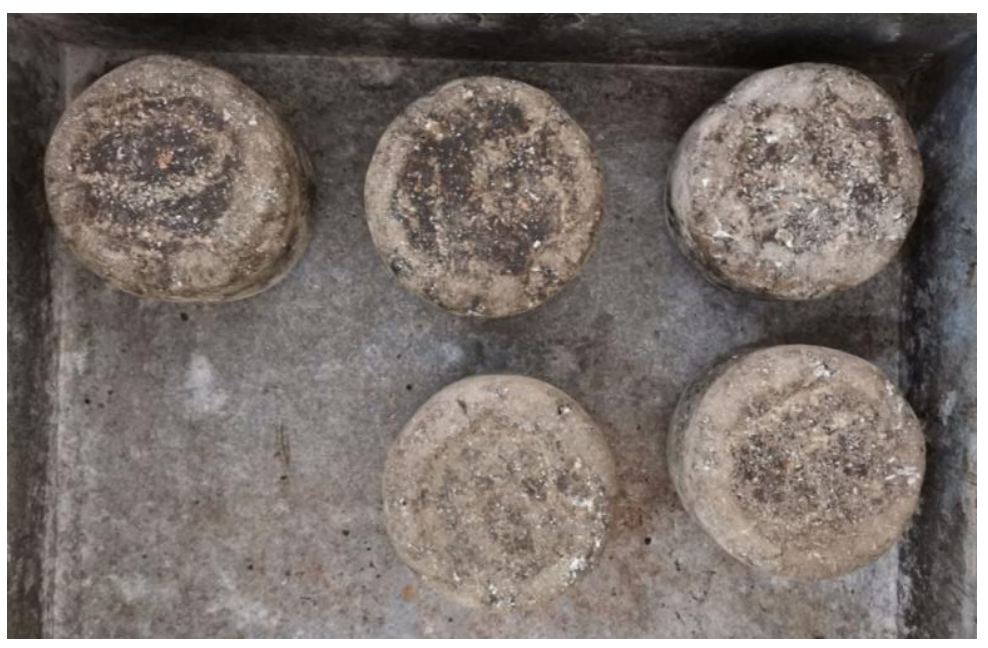

Figure 3. The sample after 300 revolutions in LA abrasion

\section{RESULTS AND DISCUSSIONS}

\section{Aggregate Properties}

Based on Table 2, the aggregate has more strength on aggregate impact value which only $22.10 \%$ and has low effect on impaction compared to eggshell which is $93.34 \%$. It shows that eggshell does not have ability to resist sudden shock or impact. The aggregate impact value for aggregate is in between $20 \%$ to $30 \%$ which meet the requirement of Malaysian Standard Specification for Road Works. However, the requirement does not specify limitation values for asphalt mixture incorporated waste agriculture waste, especially eggshell. It also same with aggregate crushing value where the aggregate have enough strong to resist crushing under traffic wheel loads which the percentage loss only $9.38 \%$ compared to eggshell which is $74.66 \%$. The aggregate crushing value for aggregate should be less than $25 \%$ and the result is meet the requirement of Malaysian Standard Specification for Road Works. However, the requirement does not specify limitation values for asphalt mixture incorporated waste agriculture waste, especially eggshell. 
Table 2. Aggregates properties results

\begin{tabular}{cccc}
\hline Properties & Aggregates & Eggshell & Requirement values \\
\hline Aggregate Impact Value & $22.10 \%$ & $93.34 \%$ & $20 \%-30 \%$ \\
Aggregate Crushing Value & $9.38 \%$ & $74.66 \%$ & $<25 \%$ \\
\hline
\end{tabular}

\section{Bitumen Properties}

Bitumen 60/70 penetration grade was used in this study. Based on Table 3, the average of softening point is $54.6^{\circ} \mathrm{C}$ and the average of penetration is $65.5 \mathrm{~mm}$ where meet the JKR Specification for bitumen grade $60 / 70$.

Table 3. Bitumen properties results

\begin{tabular}{ccc}
\hline Properties & JKR Specification & Result \\
\hline Softening Point & $49^{\circ} \mathrm{C}-56^{\circ} \mathrm{C}$ & $54.6^{\circ} \mathrm{C}$ \\
Penetration & $60 \mathrm{~mm}-70 \mathrm{~mm}$ & $65.5 \mathrm{~mm}$ \\
\hline
\end{tabular}

\section{Stability}

Stability verifies the performance of the asphalt mixture under loading. The Figure 4 shows the relationship between stability and percentage of eggshell. The stability of conventional asphalt mixture is higher than modified asphalt mixture. This is because eggshell has lower strength compared to aggregates. For modified asphalt mixture, the stability of 5\% eggshell is the highest with $12.36 \mathrm{kN}$ and slightly decreases with the increase of eggshell. A lower stability value occurred for modified asphalt mixture with $10 \%$ of eggshell with $9.59 \mathrm{kN}$. Thus, $5 \%$ of eggshell is the most stable because it gives the highest stability value compared to other percentage of eggshell. The results showed that eggshell can increase the stability of the asphalt mixture up to certain percentages and after that it will decrease. So, according to the Malaysian Standard Specification for Road Works [11], the data from Figure 4 which is 0\%, 5\%, 10\%, 15\%, and $20 \%$ of eggshell with the stability of $17.75 \mathrm{kN}, 12.36 \mathrm{kN}, 9.59 \mathrm{kN}, 9.90 \mathrm{kN}$ and $11.816 \mathrm{kN}$ meet the specification, where all the stability greater than $8 \mathrm{kN}$.

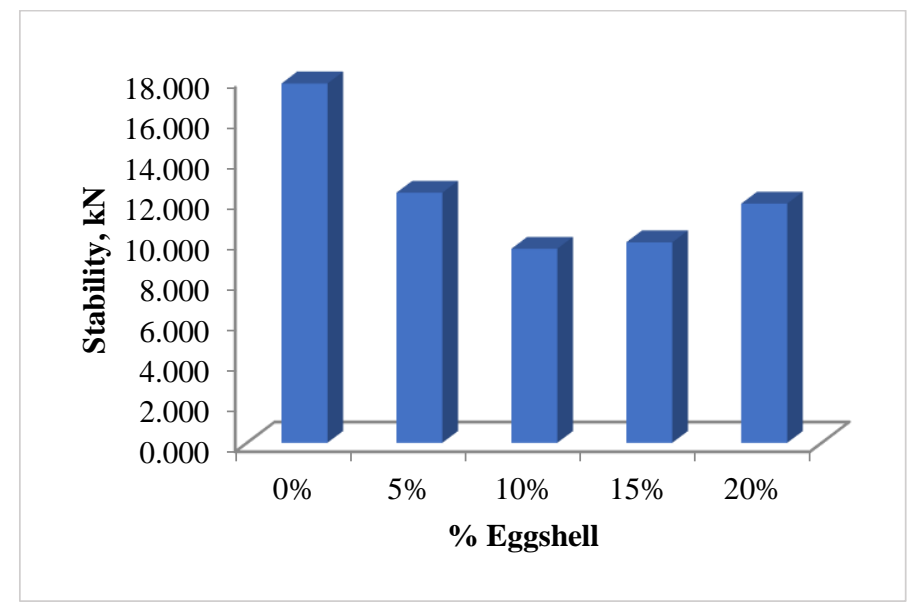

Figure 4. Stability of asphaltic concrete at different percentage of eggshell

Flow

Figure 5 shows the graph of flow against the percentage of eggshell. The flow value of modified asphalt mixture is higher than conventional mixture. The highest flow is in 5\% of modified asphalt mixture with $6.21 \mathrm{~mm}$ compare with the conventional asphalt mixture. The flow value increase when the eggshell presence in the mixture. However, for flow $10 \%$ of eggshell decrease which is cause low flow. According to the Malaysian Standard Specification for Road Works [11] for flow, the result must be in $2.0 \mathrm{~mm}-4.0 \mathrm{~mm}$. However, only conventional mix pass the JKR specification. All the modified mix did not pass the specification of JKR because of the high flow value and the pavement has potential for road defects and permanent deformation, such as rutting or shoving, under loading. 


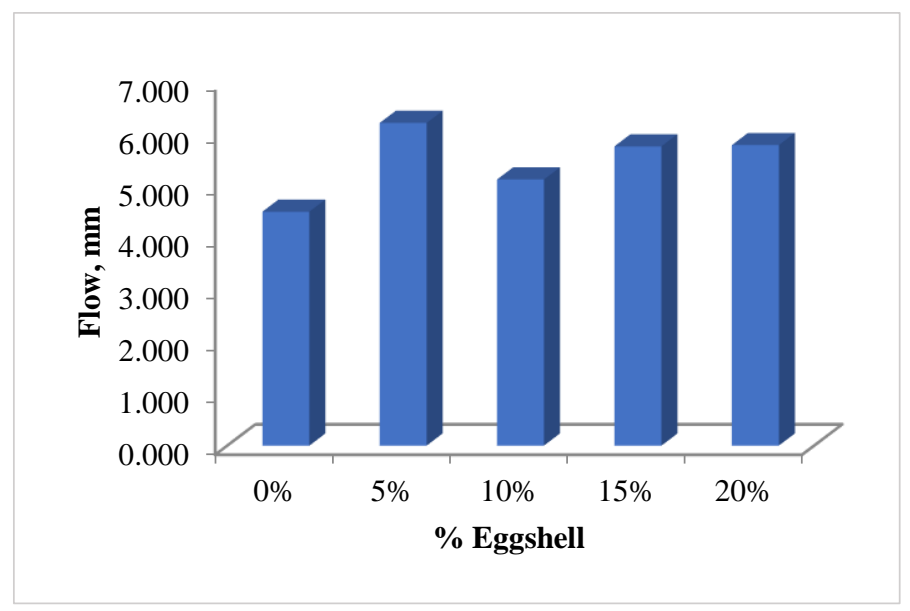

Figure 5. Flow of asphaltic concrete at different percentage of eggshell

\section{Stiffness}

Stiffness is a measurement that indicates the ratio of the stability to the flow. Figure 6 shows the graph of stiffness of asphaltic concrete at different percentage of eggshell. The stiffness value of conventional asphalt mixture is higher than modified asphalt mixture. According to the Malaysian Standard Specification for Road Works [11], for stiffness the result must greater than $2 \mathrm{kN} / \mathrm{mm}$. The stiffness for conventional asphalt mixture is $3.89 \mathrm{kN} / \mathrm{mm}$. For modified asphalt mixture, the stiffness becomes decreases when the percentage of eggshell increases. But the stiffness increase when the percentage of eggshell is $20 \%$ with stiffness value $2.08 \mathrm{kN} / \mathrm{mm}$. The stiffness value for conventional $0 \%$ and $20 \%$ of eggshell meet the JKR/SPJ/2008-S4 specification. However, the stiffness value of 5\%, 10\% and $15 \%$ of eggshell where are $1.98 \mathrm{kN} / \mathrm{mm}$, $1.88 \mathrm{kN} / \mathrm{mm}$ and $1.72 \mathrm{kN} / \mathrm{mm}$ did not meet the Malaysian Standard Specification for Road Works [11].

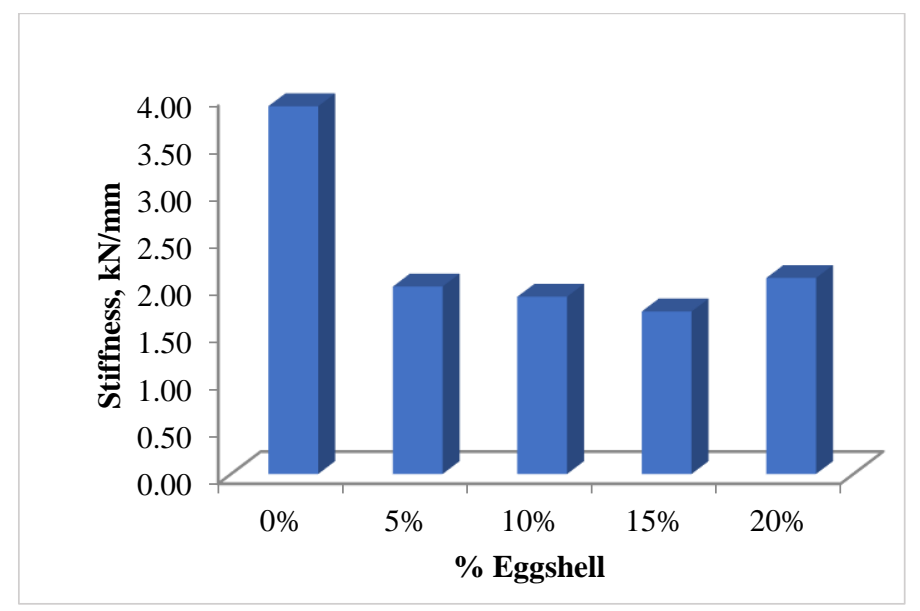

Figure 6. Stiffness of asphaltic concrete at different percentage of eggshell

\section{Bulk Density}

Figure 7 shows that the bulk density of asphaltic concrete at different percentage of eggshell. The bulk density value of modified asphalt mix is higher than conventional mix. The bulk density decrease with the increasing of eggshell content. This is due to the bitumen filling in the void space of the aggregate particle. The increase in eggshell content related to the increased bitumen being absorbed by the eggshell leading to extensive voids space with the aggregate particles, hence a decrease in mix density. Result for conventional asphalt mixture the bulk density is $2.32 \mathrm{~g} / \mathrm{mm}$ compared to $5 \%, 10 \%, 15 \%$ and $20 \%$ of eggshell, the results is $2.38 \mathrm{~g} / \mathrm{mm}, 2.37 \mathrm{~g} / \mathrm{mm}, 2.36 \mathrm{~g} / \mathrm{mm}$ and $2.36 \mathrm{~g} / \mathrm{mm}$. There are no specifying limitation values for bulk density in Malaysian Standard Specification for Road Works [11] for asphaltic concrete containing waste materials. 


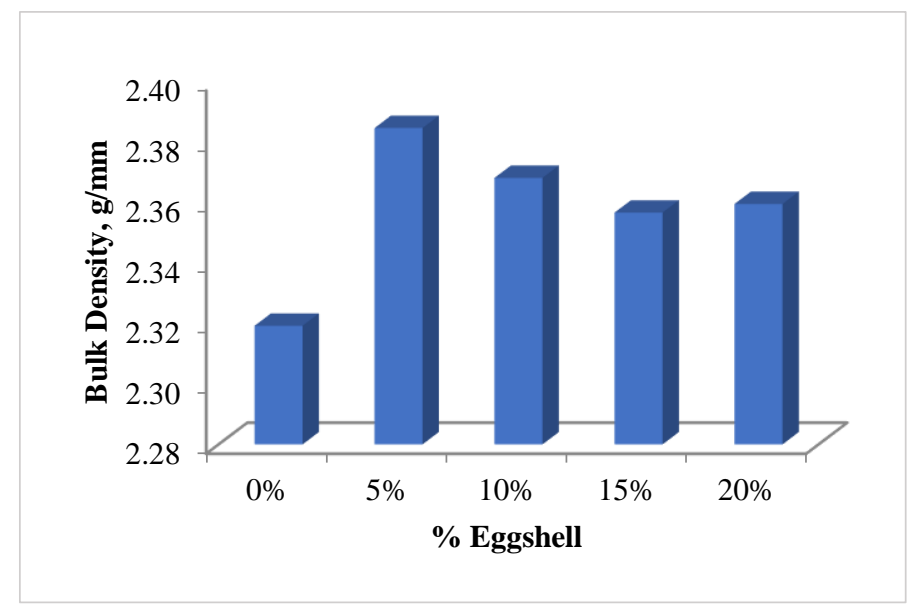

Figure 7. Bulk density of asphaltic concrete at different percentage of eggshell

\section{Air Voids}

Air voids are the important factor to correlate results to performance of the asphalt pavements. The amount of air voids affected the stability and durability of the mix. Voids are the spaces in the samples that are left even after the compaction has been done. If the compacted mix has a high air void content, which is greater than 5\% the mix will not perform as well under traffic. Similarly if the compacted mix has a low air-void content which is less than $3 \%$, the mix will be susceptible to permanent deformation or rutting and also to distortion under the applied traffic loads. A proper percentage of air voids is necessary to prevent the pavement from flushing, shoving and rutting.

Figure 8 presented the effect of air voids at different percentage of eggshell. From the Figure 8, the air voids of conventional asphalt mixture is higher than modified asphalt mixture. The air voids for conventional asphalt mixture is $4 \%$. For modified asphalt mixture, the air voids are increases when the percentage of eggshell increases but decrease when the percentage of eggshell is $20 \%$. The highest value of air voids for modified asphalt mixture is $15 \%$ of eggshell with $2.45 \%$, followed by $20 \%$ eggshell with $2.335 \%, 10 \%$ eggshell with $1.98 \%$ and the lowest is $5 \%$ of eggshell with $1.30 \%$. According to the Malaysian Standard Specification for Road Works [11], the data of air voids for conventional asphalt mixture is meet the requirement, but for modified asphalt mixture the value does not meet the requirement which the value is less than the design range of air voids $3-5 \%$.

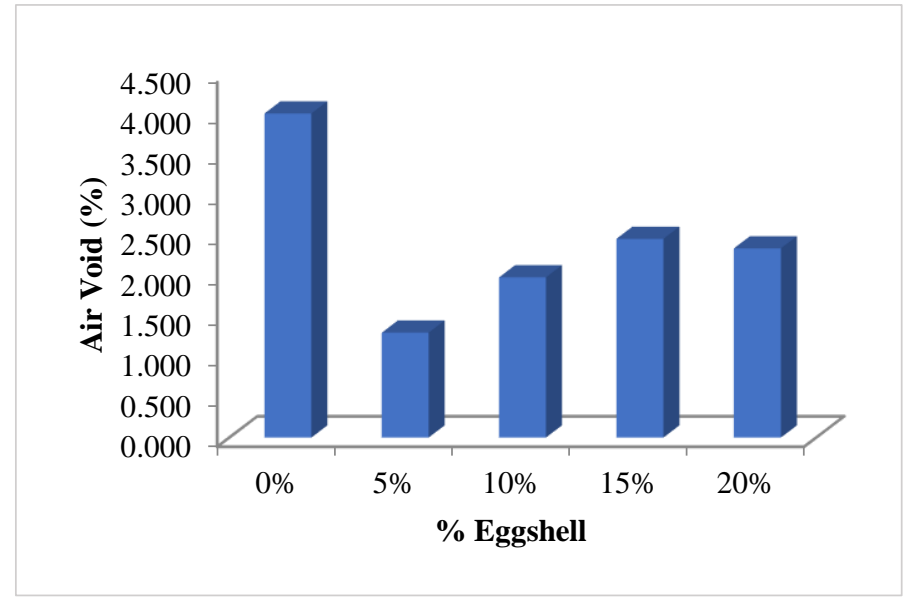

Figure 8. Air voids of asphaltic concrete at different percentage of eggshell

\section{Voids Filled with Asphalt (VFA)}

The VFA is the percentage of voids in the compacted aggregate mass that are filled with asphalt binder. VFA determined by amount of VMA and air voids in the mixture. The higher values of the VMA, the smaller values of the VFA can be obtained. VFA is purposed to avoid less durable HMA resulting from thin films of binder on the aggregate particles in light traffic situations. Low air void contents may be very critical in terms of permanent deformation, the VFA requirement helps to avoid those mixes that are susceptible to rutting in heavy traffic situations. If the VFA is too low, there is not enough asphalt to provide durability and to over-densify under traffic and bleed. However, if VFA exceed approximately $80 \%$ and above, the dense mix typically becomes unstable and rutting is likely to occur.

Figure 9 shows the percentage of voids filled with asphalt. The modified asphalt mixture has highest value than conventional asphalt mixture. By refer the Figure 9, the VFA for conventional asphalt mixture is $73.97 \%$ and for 5\%, $10 \%, 15 \%$ and $20 \%$ of eggshell the results are $89.94 \%, 85.34 \%, 82.36 \%$ and $83.17 \%$. Based on the Malaysian Standard 
Specification for Road Works [11], to pass the standard, the voids filled with asphalt must be in the range of 70-80\%. From the analysis above, the samples that passed the parameter set is conventional asphalt mixture that contained $0 \%$ of eggshell with a $73.97 \%$ voids filled with asphalt.

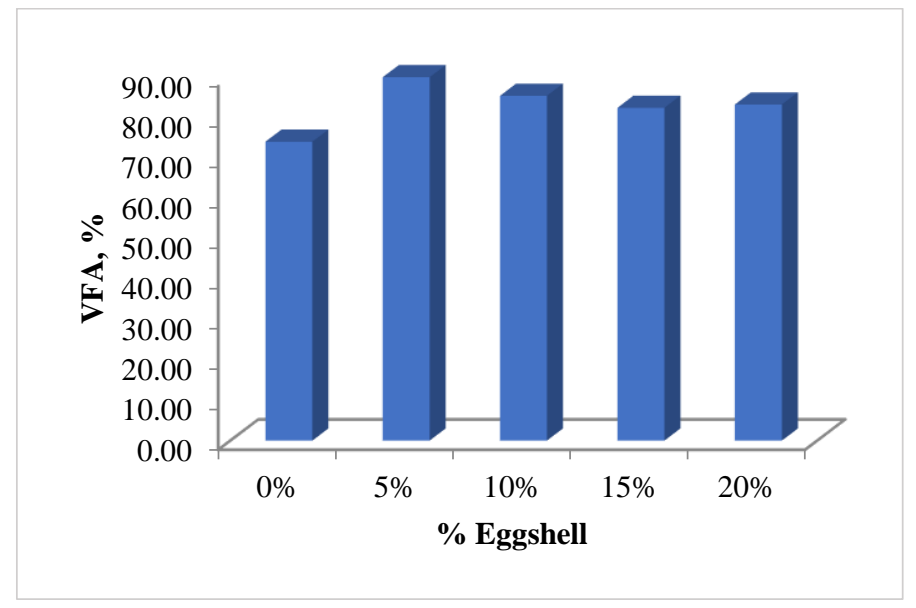

Figure 9. VFA of asphaltic concrete at different percentage of eggshell

\section{Voids in the Mineral Aggregates (VMA)}

The voids in mineral aggregate is the total volume of voids within the mass of sample with the sample is compacted. VMA is important to allow room for enough asphalt binder to make a durable mixture plus enough room for mixture air voids to ensure stable mixture. If percentage VMA in sample is low thus is a high possibility the binder cannot fully coated the aggregate in a mix. A durable asphalt mixture requires an adequate film thickness in a mixture. If the VMA amount is too large, an uneconomical amount of asphalt binder will be required to reduce the mixture air voids to an acceptable level. This amount of asphalt binder in the mixture may also lead to mixture stability problems. As the nominal maximum particle size of the aggregate increases, the minimum VMA required decreases. This occurs because the total void space between large aggregate particles is smaller than the void space between small aggregate particles.

The voids in the mineral aggregate values of asphaltic concrete at varying percentage of eggshell are illustrated in Figure 10. The VMA of conventional asphalt mixture is higher than modified asphalt mixture. It can be seen that the VMA values of specimens are increase by increasing eggshell content. The value of conventional asphalt mixture is $15.26 \%$. The highest VMA among the modified asphalt mixture is $15 \%$ of eggshell with $13.89 \%$, followed by $20 \%$ eggshell with $13.79 \%$, $10 \%$ eggshell with $13.47 \%$ and the lowest VMA is 5\% of eggshell with $12.87 \%$. There are no specifying limitation values for VMA in Malaysian Standard Specification for Road Works [11] for asphaltic concrete containing waste materials.

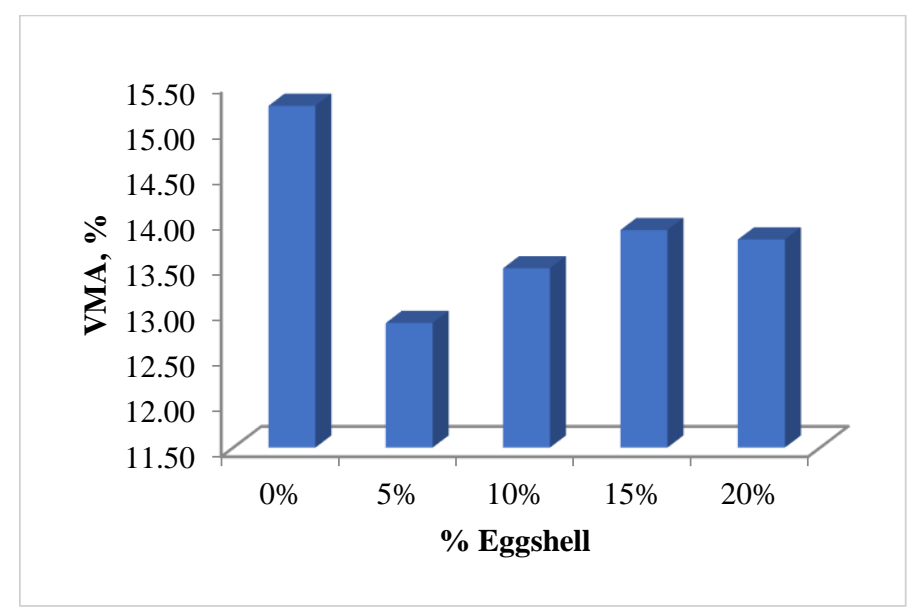

Figure 10. VMA of asphaltic concrete at different percentage of eggshell

\section{Stability and Flow}

The effect of eggshell on stability and flow is illustrated in Figure 11. Generally, the stability decreases as increasing the percentage of eggshell. Conventional asphalt mixture recorded that the higher stability was $17.75 \mathrm{kN}$ while the lowest stability is $9.59 \mathrm{kN}$ at $10 \%$ eggshell. Stability determines the performance of asphaltic concrete under loads. According to Olanipekun et al [17], the stability of the mixture depends on the cohesion of bitumen where bonding ability increase with increasing bitumen content. It can be seen that $10 \%$ eggshell are very easy to crack, brittle and cannot stand high 
load and has low strength. On the other hand, the results also show that flow for the various percentage of eggshell is increase. However, for flow $10 \%$ of eggshell decrease which is cause low flow. Low flow values may related to the low air voids. This is due to more voids presenting in the specimen and make it easy to crack under loading.

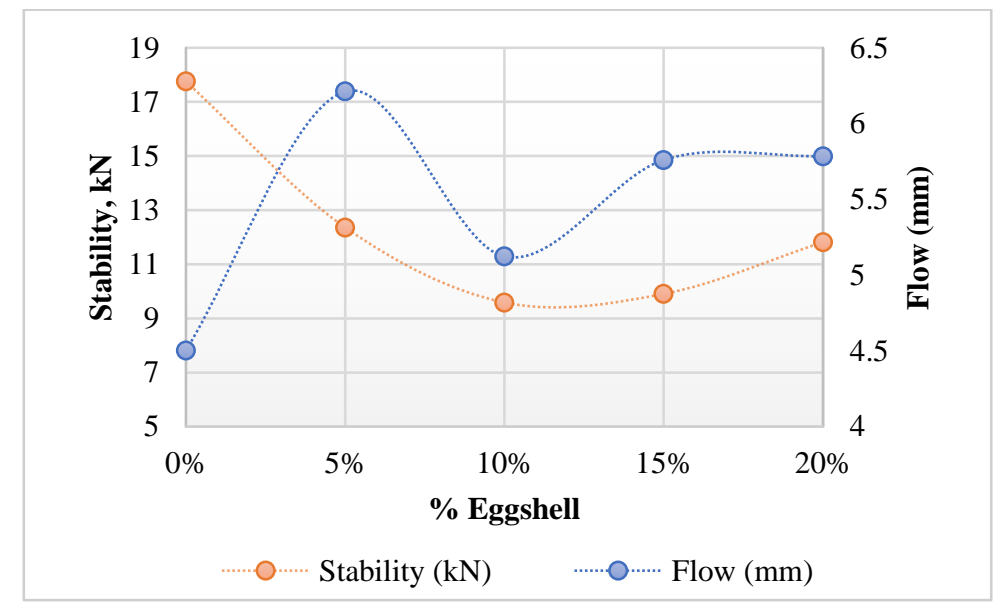

Figure 11. Stability and flow of asphalt mixture vs eggshell

\section{Stability and Bulk Density}

The effect of eggshell on stability and bulk density is shown in Figure 12. Generally, the stability decreases as increasing the percentage of eggshell. Conventional asphalt mixture recorded that the higher stability was $17.75 \mathrm{kN}$ while the lowest stability is $9.59 \mathrm{kN}$ at $10 \%$ eggshell. Stability determines the performance of asphaltic concrete under loads. According to Olanipekun et al [17], the stability of the mixture depends on the cohesion of bitumen where bonding ability increase with increasing bitumen content. It can be seen that $10 \%$ eggshell are very easy to crack, brittle and cannot stand high load and has low strength. On the other hand, the results also show that bulk density for the various percentage of eggshell is decrease with the increasing of eggshell content. This is due to the bitumen filling in the void space of the aggregate particle. The increase in eggshell content related to the increased bitumen being absorbed by the eggshell leading to extensive voids space with the aggregate particles, hence a decrease in mix density.

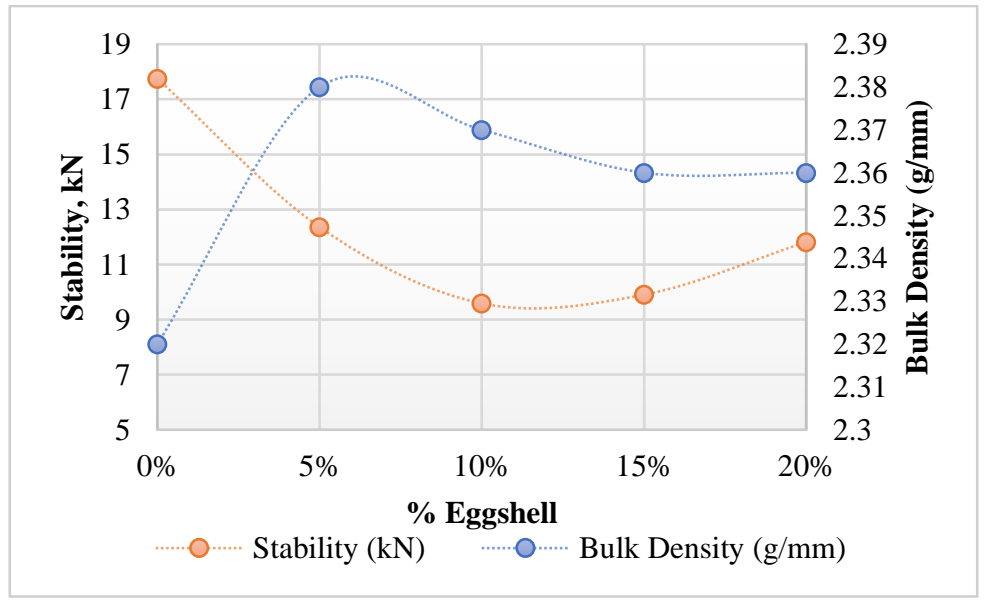

Figure 12. Stability and bulk density of asphalt mixture vs eggshell

\section{Indirect Tensile Strength}

The indirect tensile strength result are graphically shown in Figure 13. Based on the figure, the tensile strength of conventional asphalt mixture is higher than modified asphalt mixture. The tensile strength for conventional asphalt mixture is $851.18 \mathrm{kPa}$. The highest tensile strength among the modified asphalt mixture is $10 \%$ of eggshell with $801.79 \mathrm{kPa}$, followed by $5 \%$ eggshell with $739.19 \mathrm{kPa}, 15 \%$ eggshell with $722.38 \mathrm{kPa}$ and the lowest tensile strength is $20 \%$ of eggshell with $553.15 \mathrm{kPa}$. On the other hand, ITS can be seen increased with the increase in eggshell content and started to decrease at $15 \%$ eggshell which recorded the tensile strength of $10 \%$ eggshell asphalt mixture as an optimum performance. It is shows that the modified asphalt mixture with $10 \%$ eggshell has more quality bituminous and less potential for cracking than others modified asphalt mixture. 


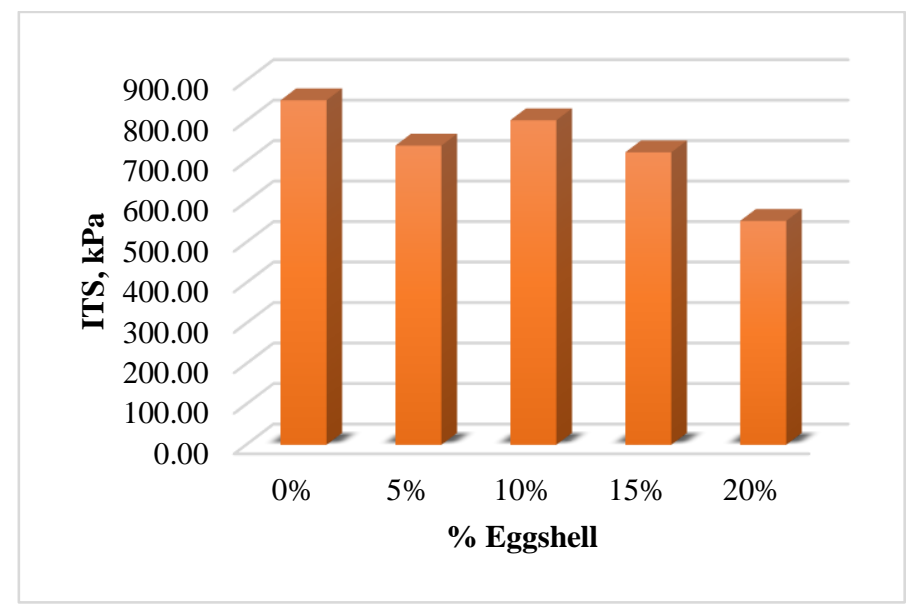

Figure 13. Effect of different percentage eggshell to indirect tensile strength

\section{Cantabro Test}

The result taken when 50 revolutions for each sample until 300 revolutions. From the Figure 14, the Cantabro Loss of conventional asphalt mixture is higher than modified asphalt mixture. The initial weight for conventional asphalt mixture is $1235.97 \mathrm{~g}$ and the final weight after 300 revolution is $1192.38 \mathrm{~g}$ with $3.53 \%$ loss. The highest cantabro loss among the modified asphalt mixture is $10 \%$ of eggshell with $2.73 \%$ loss, followed by $5 \%$ eggshell with $1.61 \%$ loss, $15 \%$ eggshell with $1.51 \%$ loss and the lowest loss angeles abrasion value is $20 \%$ of eggshell with $1.46 \%$ loss. On the other hand, the percentage of cantabro loss can be seen increased with the increase in eggshell content and started to decrease at $15 \%$ eggshell which recorded the cantabro loss of $10 \%$ eggshell asphalt mixture as an optimum loss. The initial weight for modified asphalt mixture with $10 \%$ eggshell is $1258.26 \mathrm{~g}$ and the final weight is $1223.93 \mathrm{~g}$ after 300 revolutions.

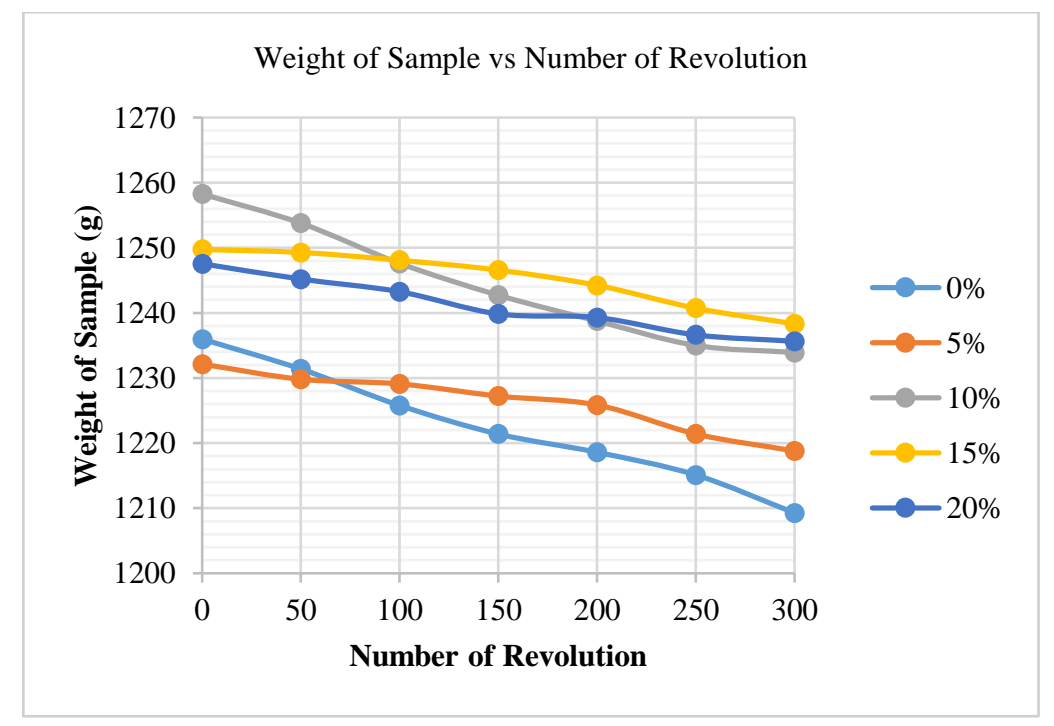

Figure 14. Graph of Cantabro Loss

\section{CONCLUSION}

The influence of eggshell as coarse aggregate replacement in hot mix asphalt was investigated. It can be seen that the different percentage of eggshell as coarse aggregate replacement in Hot Mix Asphalt had noticeably different effects on the performance of modified mixture.

a. The replacement of eggshell as coarse aggregate was not enough improvement to the performance of asphalt pavement as the performance of conventional mixture is more stable than modified mixture.

b. The Marshall properties obtained showed that stability decreased when the percentage of eggshell increased.

c. Density also decreased by increasing the percentage of eggshell in hot mix asphalt.

d. Other volumetric properties, such as VMA and VFA, also slightly decreased as the percentage of eggshell increased.

e. The replacement of eggshell as coarse aggregate in asphalt mixture makes the value of indirect tensile strength decreased. 
f. Optimum percentage of eggshell was determined based on the indirect tensile strength. The percentage of $10 \%$ eggshell presented the best results because the values fell within the acceptable range according to JKR Specification.

\section{ACKNOWLEDGEMENT}

The support provided by Malaysian Ministry of Higher Education and Universiti Malaysia Pahang in the form of a research grant vote number PGRS2003172 for this study is highly appreciated.

\section{REFERENCES}

[1] Yaacob, H., Hainin, M.R., Safuan, A., \& Chang, F.L., 2014. Information for the Malaysian asphalt industry towards better pavement interlayer bonding. Sains Malaysiana 43, 467-474.

[2] Ibraheem, 2011. Evaluation of Common Maintenance Methods for Flexible Pavements. American Journal of Engineering and Applied Sciences 4, 413-424. doi:10.3844/ajeassp.2011.413.424.

[3] Nair Baskara, S., Yaacob, H., M. R., \& Hassan, S.A., 2016. Accident due to pavement condition - A review. Jurnal Teknologi. doi:10.11113/jt.v78.9494.

[4] Tan, AW. 2016. China Press. chinapress.com.my/?p=723101. (24 June 2016).

[5] Faridi, H., \& Arabhosseini, A., 2018. Application of eggshell wastes as valuable and utilizable products: A review. Research in Agricultural Engineering 64, 104-114. doi:10.17221/6/2017-RAE.

[6] Amu, O.O., \& Salami, B. a., 2010. Effect of Common Salt on Some Engineering Properties. ARPN Journal of Engineering and Applied Sciences 5, 64-73.

[7] Erfen Y B and Mohd Yunus K N B 2015 The Appropriateness of Egg Shell as Filler in Hot Mix Asphalt researchGate.

[8] Kiruthiha, K., Loshini, G., Thivya, M., \& Kumar, Mr.V., 2015. Strengthening of Flexible Pavement using Egg Shell as a Filler. International Journal of Engineering Trends and Technology 21, 483-486. doi:10.14445/22315381/ijett-v21p294.

[9] Razzaq, A.K., Yousif, R.A., \& Tayh, S.A., 2018. Characterization of hot mix asphalt modified by egg shell powder. International Journal of Engineering Research and Technology 11, 481-492.

[10] Yuliarahmadila Binti Erfen, Khairul Nizam Bin Mohd Yunus, July 2015. The Appropriateness of Eggshell as filler in hot mix Asphalt. DOI: 10.13140/RG.2.1.4113.5201.

[11] JKR, 2008. JKR/SPJ/2008-S4 Standard Specification for Road Works Part4 Flexible Pavement. JKR Specification for Road Works Part4 Flexible Pavement 07, 1-187.

[12] BS EN 1097-2:2020. Tests for mechanical and physical properties of aggregates. Part 2: Methods for the determination of resistance to fragmentation. British Standard 34p.

[13] BS EN 1427, 2015, "Bitumen and bituminous binders — Determination of the softening point — Ring and Ball method". British Standards Institution: London, United Kingdom.

[14] BS EN 1426, 2015, "Bitumen and bituminous binders - Determination of needle penetration", British Standards Institution: London, United Kingdom.

[15] ASTM Standard D2726, 2014. Standard Test Method for Bulk Specific Gravity and Density of Non-Absorptive Compacted Bituminous Mixtures. Www.Astm.Org 04, 1-4.

[16] ASTM D6931-12, 2017. Standard Test Method for Indirect Tensile ( IDT ) Strength of Bituminous Mixtures. ASTM International 1-5.

[17] Olanipekun, E.A., Olusola, K.O., \& Ata, O., 2006. A comparative study of concrete properties using coconut shell and palm kernel shell as coarse aggregates. Building and Environment 41, 297-301. doi:10.1016/j.buildenv.2005.01.029. 